\section{New products and focus on implants and private practice}

\section{BREAKTHROUGH IN BONE GRAFTING}

BondBone $^{\mathrm{TM}}$ from MIS UK is a unique synthetic bone graft material considered to be a breakthrough in the field of dental bone grafting.

It is composed of a biphasic calcium sulphate, which has well established and documented biocompatible, osteoconductive and bioresorbable properties. The biphasic calcium sulphate is fast setting, stable and its physical properties are not affected by the presence of blood and saliva.

BondBone $^{\mathrm{TM}}$ can be used in three different ways. It can be mixed with other granular bone grafting materials, preventing particle migration in an

\section{PROVEN PROSTHETIC SOLUTION}

Implant bar supported dentures are a proven prosthetic solution and NobelProcera $^{\mathrm{TM}}$ from Nobel Biocare takes them to a new restorative level.

NobelProcera $^{\mathrm{TM}}$ bars set new standards. They are individually designed using 3D prosthetic driven software, industrially milled from a solid biocompatible monobloc of titanium and delivered highly polished and ready to use. Thanks to precision milling, these bars exhibit exceptional fit, ideal load osseous defect and creating an excellent composite graft; it can be used alone in defects that are less than $10 \mathrm{~mm}$ with at least three wall bony support; or it can be used as a barrier over other bone grafting materials.

In most cases BondBone ${ }^{\mathrm{TM}}$ does not require membrane coverage. The initially pliable paste hardens in two to five minutes, allowing excellent handling time, and its setting is not affected by the presence of blood and saliva. BondBone ${ }^{\mathrm{TM}}$ is pure and safe, containing nothing other than calcium sulphate, and it completely resorbs leaving behind natural bone.

Reader response number 50

transfer and long-term stable screw joints. In addition, a TorqTite ${ }^{\circledR}$ clinical carbon-coated titanium screw is supplied which provides a stable long-term screw connection and ideal preload conditions.

NobelProcera $^{\mathrm{TM}}$ implant bars offer excellent versatility and are suitable for a wide variety of attachment types, therefore meeting the requirements of most clinical situations. The bars are subject to stringent quality controls and come with a five-year warranty. Reader response number 51

\title{
ASSOCIATION OF DENTAL IMPLANTOLOGY
}

The Association of Dental Implantology UK (ADI) runs a successful and popular programme of implantology events and courses.

Next in the ADI calendar is a Masterclass with Ken Hebel on Friday 12 November 2010 at the Cavendish Con- ference Centre in London. Registrations will also open shortly for the ADI Team Congress 2011, which will take place at the Manchester Central Convention Complex on 14-15 April and will feature inspirational speakers from around the world.
Please send trade news information and illustrations to Arveen Bajaj at the $B D J$, Nature Publishing Group, The Macmillan Building, 4-6 Crinan Street, London N1 9XW. Trade news is provided as a service to reader using text and images from the manufacturer, supplier or distributor and does not imply endorsement by the $B D J$. Normal and prudent research should be exercised before purchase or use of any product mentioned.

\section{RAPID RELIEF FOR SENSITIVE TEETH}

Sensodyne has released new Sensodyne Rapid Relief toothpaste for patients with dentine hypersensitivity. When the strontium acetate formula of Sensodyne Rapid Relief is massaged on to the base of the sensitive tooth for 60 seconds, patients get rapid relief from their sensitivity. Long-lasting protection can be achieved by regular twice daily brushing.

Sensodyne Rapid Relief is clinically proven. The strontium acetate formulation works by creating deep, acid-resistant occlusion of the dentinal tubules, even after a 10 minute acid challenge. The toothpaste also contains sodium fluoride.

Trial size packs of Sensodyne Rapid Relief for your dental patients are available on request.

Reader response number 52

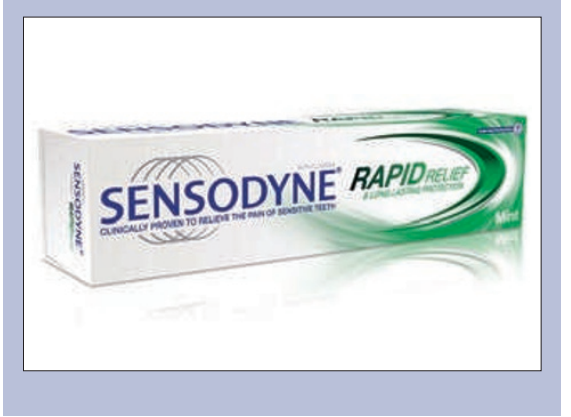

Membership of the ADI brings many benefits including reduced cost of attending all ADI events and study clubs. Also available to clinician and technician members is access to ADIA, a complimentary online audit software that meets GDC guidelines on the auditing of patients.

Reader response number 53 